NBER WORKING PAPER SERIES

\title{
DIRECT OR INDIRECT TAX INSTRUMENTS FOR REDISTRIBUTION: SHORT-RUN VERSUS LONG-RUN
}

\author{
Emmanuel Saez \\ Working Paper 8833 \\ http://www.nber.org/papers/w8833 \\ NATIONAL BUREAU OF ECONOMIC RESEARCH \\ 1050 Massachusetts Avenue \\ Cambridge, MA 02138 \\ March 2002
}

I thank Peter Diamond, Thomas Piketty, and David Spector for helpful discussions. The views expressed herein are those of the author and not necessarily those of the National Bureau of Economic Research.

(C) 2002 by Emmanuel Saez. All rights reserved. Short sections of text, not to exceed two paragraphs, may be quoted without explicit permission provided that full credit, including (C) notice, is given to the source. 
Direct or Indirect Tax Instruments for Redistribution:

Short-run versus Long-run

Emmanuel Saez

NBER Working Paper No. 8833

March 2002

JEL No. H21, H23

\begin{abstract}
Optimal tax theory has shown that, under weak assumptions, indirect taxation such as production subsidies, tariffs, or differentiated commodity taxation, are sub-optimal and that redistribution should be achieved solely with the direct income tax. However, these important results of optimal tax theory, namely production efficiency and uniform commodity taxation under non-linear income taxation, have been shown to break down when labor taxation is based on income only and when there is imperfect substitution of labor types in the production function. These results in favor of indirect tax instruments are valid in the short-run when skills are exogenous and individuals cannot move from occupation to occupation. In the long-run, it is more realistic to assume that individuals choose their occupation based on the relative after-tax rewards. This paper shows that, in that context, production efficiency and the uniform commodity tax result are restored. Therefore, in a long-run context, direct income taxation should be preferred to indirect tax instruments to raise revenue and achieve redistribution.
\end{abstract}

Emmanuel Saez

Harvard University Department of Economics

Littauer

Cambridge, MA 02138

and NBER

saez@fas.harvard.edu 


\section{Introduction}

The theory of optimal taxation has derived a number of powerful properties of optimal tax structures. First and perhaps most important is the production efficiency result of Diamond and Mirrlees (1971). This result states that the economy should be on its production frontier at the optimum when the government can tax (linearly) all factors (inputs and outputs) at different rates and when there are no pure profits (or when pure profits can be fully taxed). This result has two very important public policy implications. First, the public sector should optimize its production decisions using market prices. Second, the government should not use tariffs, production taxes or subsidies because they create production inefficiencies.

Second, Atkinson and Stiglitz (1976) showed that there is no need to use commodity taxation when the government can use a non-linear income tax and utility functions are weakly separable between goods and leisure. Atkinson and Stiglitz proved their theorem using a fixed priced model with perfect substitution between different types of labor. This result has been applied in many instances and has notably been used to show that, under plausible assumptions, capital taxation is not necessary when labor income can be taxed non-linearly.

These two results combined have a very strong and simple tax policy implication. Indirect tax instruments such as production subsidies, tariffs, or differentiated commodity taxation, are sub-optimal and redistribution should be achieved solely with the direct income tax.

Third, Diamond and Mirrlees (1971) showed another important result for the theoretical analysis of optimal tax structures, namely that optimal tax formulas are identical when prices of factors are fixed, as in a small open economy, and when prices are variable and derived from a general production function. This result is important because it implies that substitution between inputs in the production function can be ignored when deriving optimal tax formulas. This simplifies considerably the analysis. From now on, we call this result the Tax-Formula result. ${ }^{1}$

However, these three important results of optimal tax theory have been challenged by subsequent studies. Stiglitz (1982) has developed a simple two-type model (skilled and unskilled workers), where the government cannot observe workers' skills and has to base taxation on in-

\footnotetext{
${ }^{1}$ This result has received much less attention in the literature than the previous two results because it does not have such important practical tax policy implications.
} 
come only. In that situation, the government cannot impose freely differentiated tax rates on each type of labor as in the Diamond-Mirrlees model and the Tax-Formula result breaks down. In the model of Stiglitz (1982), there is imperfect substitution of labor types in the production function and the optimal tax formulas depend explicitly on the elasticity of substitution between skilled and unskilled labor. Stiglitz (1982) point is important because it shows that the standard properties of the optimal non-linear income tax model of Mirrlees (1971), such as the zero top result or the positivity of the marginal tax rate, obtained under the assumption perfect substitution between labor types are not robust to the relaxation of this assumption.

Recently, Naito (1999) has shown that, in the framework of the Stiglitz (1982) model where there is imperfect substitution of labor types in the production function and the government has to base taxation on income only, the production efficiency result of Diamond and Mirrlees (1971) and the theorem of Atkinson and Stiglitz (1976) on commodity taxation also break down. The production efficiency result breaks down because the government cannot apply differentiated rates on each type of labor and thus the taxation power of the government is restricted compared to the Diamond-Mirrlees model. ${ }^{2}$ The Atkinson-Stiglitz Theorem breaks down because of imperfect substitution in labor types. In that case, manipulating indirectly wages through commodity taxation enhances the redistributive power of the income tax and is thus desirable.

Therefore, relaxing two assumptions in a natural way is enough to loose the three main results of optimal taxation theory. The first of these two assumptions is perfect substitution of labor inputs in the production function. The second assumption is the possibility to condition wage income tax rates on labor type. From now on, this second assumption is called the labor types observability assumption. Both the Tax-Formula result and the production efficiency result of Diamond and Mirrlees (1971) are valid with imperfect substitution of labor types but no longer when the labor types observability assumption is relaxed. The Atkinson-Stiglitz theorem is valid without labor types observability but not when the perfect substitution of labor types assumption is relaxed. Naito's (1999) contribution is important, not only because it shows that the key results of optimal tax theory are not robust to the relaxation of two assumptions that

\footnotetext{
${ }^{2}$ Guesnerie (1998) provides an analysis close to Naito (1999) along those lines.
} 
clearly do not hold in the real situation, ${ }^{3}$ but mostly because it gives a clear sense of how the indirect tax instruments should be used to complement income taxation. When the government cares about redistribution, tariffs on low skill labor intensive goods, production subsidies for low skilled intensive goods, or commodity taxes on high skill labor intensive goods, are desirable. Therefore, indirect taxation should supplement income taxation in the direction one would expect, and thus Naito's results provide a convincing rationale for using a variety of indirect tax instruments.

The present paper argues that the negative results of Stiglitz (1982) and Naito (1999) hinge crucially on the way labor supply behavioral responses are modeled. In both of these papers, workers are intrinsically either skilled or unskilled and respond to incentives by varying their hours of work. In that case, manipulating indirectly wages through tariffs, production subsidies or commodity taxation enhances redistribution because these indirect instruments help overcome the informational constraints that arise with the use of the income tax. This model might be an accurate description of labor responses in the short run once individuals have chosen their education decisions and type of jobs.

However, in the long-run, when relative wages between occupations change, the adjustment does not go through changes in individual hours of work but rather through changes in relative entry levels by occupation. For example, if an industry becomes obsolete because of technological progress, then the wages in that particular industry decline and supply for this type of occupation dwindles. The adjustment of hours or work at the individual level is in this case of second order of importance in the long run. Therefore, in the long run, it seems more natural to assume that individuals choose their job depending on the (after-tax) rewards that each type of job is giving. Even in the medium run, individuals may react to taxation through occupational changes or intensity of work to climb up the career ladder rather than keeping the same occupation and varying only the amount of work.

This paper shows that, in the context of a job choice model, the three results of optimal taxation, namely the Tax-Formula result, Production Efficiency, and the Atkinson-Stiglitz Theorem, remain valid when both the perfect substitution of labor types and wage type observability

\footnotetext{
${ }^{3}$ Diamond and Mirrlees (1971) were aware that the assumption that the government could tax each input or output at specific rates was critical for their result.
} 
assumptions are relaxed. Intuitively, in the long run or occupational choice model, as hours of work are fixed, income is directly proportional to the wage rate and therefore, the income tax is equivalent to a direct tax on wages and thus indirect taxation through tariffs, production subsidies or commodity taxation becomes useless. As we will discuss, the short-run or hours of work model and the long-run or occupational model can be distinguished empirically. Therefore, it should be possible to assess precisely to what extent the objections of Stiglitz (1982) and Naito (1999) to the normal theory are relevant. The result of the present paper has important policy implications because it shows that, although tariffs or production subsidies might be socially desirable in the short-run, they cannot be optimal in a long-run context. Therefore, governments with a sufficiently low discount rate should not support these policies. Though intuitively reasonable, the result is not obvious and depends in a precise way on how the behavioral responses to taxation are modeled. This set of results fits well with the actual political debate. Unions and populist parties which represent the interests of current blue collar workers tend to support indirect tax instruments such as tariffs or production subsidies while political parties or associations which represent a broader set of the population tend to prefer direct tax instruments such as the income tax or the value added tax to raise revenue and achieve redistribution.

The paper proceeds as follows. Section 2 presents a simple example to contrast the desirability of tariffs in the short-run and in the long-run. Section 3 presents the job choice model in a general way and shows that this model can be seen as a direct extension of the Diamond and Mirrlees (1971) economy, and shows why the three main results of optimal taxation are valid in that context. Finally, Section 4 offers some concluding remarks.

\section{A Simple Example}

This section shows in a very simplified context why tariffs are desirable in the short run but no longer in the long run. I first present the structure of the economy common to both situations.

There are two types of occupation in the economy. A low skill occupation produces a low technology good (for example textile) and a high skill occupation produces a high technology good (for example computers). In each sector, one unit of high (low) skilled labor produces one unit of high (low) technology good. Subscript 1 denotes the low technology good or sector and 
subscript 2 the high technology good or sector. We consider the case of a small open economy which takes as given the international prices of each good $p=\left(p_{1}, p_{2}\right)$. The small country can impose a tariff $t$ per unit on imports of good 1. Therefore the domestic prices of goods are $q=\left(q_{1}, q_{2}\right)=\left(p_{1}+t, p_{2}\right)$. We assume that the production sectors are competitive and therefore wages rates $w=\left(w_{1}, w_{2}\right)$ in each sector are equal to domestic prices $q=\left(q_{1}, q_{2}\right)$. We assume that utility is separable between consumption of goods 1 and 2, and labor choices. All individuals derive the same utility $U\left(c_{1}, c_{2}\right)$ for consuming goods 1 and 2 in quantity $c_{1}$ and $c_{2}$. The indirect utility is $v(q, x)=\max U\left(c_{1}, c_{2}\right)$ subject to $q_{1} c_{1}+q_{2} c_{2} \leq x$, where $x$ denotes after tax income. The government sets an optimal (non-linear) income tax that can be based only of total labor earnings.

As the goal of this section is to contrast the desirability of tariffs in the short-run versus the long-run, we consider two models for labor choices. The first model is a short-run or choice of hours model and the second model is a long-run or occupation choice model. In the short-run, individuals are stuck into an occupation (high skill or low skill) but can vary their labor supply (hours of work) on the job. This is classic discrete type model of optimal taxation developed by Stiglitz (1982). In the long run however, individuals choose their occupation according to the relative rewards in each occupation. As we think that the hours choice is of second order in the long run, we assume labor supply is fixed and equal to one once a type of job is chosen in the occupational choice model. This occupational model was developed by Piketty (1997) to study optimal income tax issues.

\subsection{The short-run or choice of hours model}

This model is a simplified version of the model of Naito (1996). The simplified model we use has been developed by Spector (1999) to investigate under which circumstances opening an economy to free trade improves welfare. Therefore, the model is presented quickly and only the intuitions for the results are given.

Individuals are either unskilled (type 1) or skilled (type 2). I denote by $f$ the immutable proportion of unskilled workers. Individuals choose their hours of work $l$, earn $w_{i} l$ and pay taxes $T_{i}$ according to their type $i$. Total utility is equal to $V_{i}=v\left(q, w_{i} l-T_{i}\right)-C(l)$ where $C(l)$ is an increasing and convex function of labor cost. Because, the government cannot observe types 
directly, the income tax $\left(T_{1}, T_{2}\right)$ must be incentive compatible: skilled workers must be better off working $l_{2}$ and earning $w_{2} l_{2}-T_{2}$ after taxes rather than imitating the unskilled by working $w_{1} l_{1} / w_{2}$ and earning $w_{1} l_{1}-T_{1}$. As is standard in the literature, we assume that we are in the normal redistributive case where only this incentive compatibility constraint is binding.

For a given level of tariffs $t$, the government chooses $\left(l_{1}, l_{2}, T_{1}, T_{2}\right)$ so as to maximize a weighted sum of utilities, $W=\pi_{1} f V_{1}+\pi_{2}(1-f) V_{2}$ (where $\pi_{i}$ are positive weights), subject to the incentive compatibility constraint

$$
v\left(q, w_{2} l_{2}-T_{2}\right)-C\left(l_{2}\right) \geq v\left(q, w_{1} l_{1}-T_{1}\right)-C\left(w_{1} l_{1} / w_{2}\right),
$$

and a budget constraint stating that total tax collected are at least equal to zero. ${ }^{4}$ I denote by $C_{1}$ total consumption of good 1 in the economy. As $f l_{1}$ is total production of good 1 in the economy, net imports are equal to $C_{1}-f l_{1}$. Therefore, net taxes collected by the tariff $t$ are equal to $t\left(C_{1}-f l_{1}\right)$ and the budget constraint of the government is

$$
f T_{1}+(1-f) T_{2}+t\left(C_{1}-f l_{1}\right) \geq 0
$$

At the optimum, the incentive compatibility condition (1) is binding. As usual, labor supply of the high skilled is efficient $\left(C^{\prime}\left(l_{2}\right)=w_{2}\right)$ but labor supply of the unskilled is below the efficient level $\left(C^{\prime}\left(l_{1}\right)<w_{1}\right)$. Naito (1996) showed that starting from a situation with no tariffs $t=0$, imposing a small tariff $d t>0$ increases welfare $W$. An intuitive explanation for this result can be presented as follows. ${ }^{5}$

Suppose that the government increases tariffs by $d t$, then the government collects $\left(C_{1}-f l_{1}\right) d t$ additional taxes. The tariff can be decomposed into two effects. First, the small tariff increases the price of good 1 by $d t$ as would a consumption tax $d t$ on good 1 . Second, the tariff increases the wages of the unskilled by $d t$. Therefore, the tariff is exactly equivalent to a consumption tax $d t$ on good one plus a wage subsidy $d t$ for the unskilled. ${ }^{6}$ The consumption tax part has no first order effect on welfare because of the separability assumption between goods and labor

\footnotetext{
${ }^{4}$ Assuming that a given exogenous amount a tax revenue should be collected would not change the analysis.

${ }^{5}$ Naito's derives his result from the formal analysis of the first order conditions.

${ }^{6}$ This decomposition has been introduced by Dixit and Norman $(1980,1986)$.
} 
costs. This result is a particular case of the general result of Atkinson and Stiglitz (1976). ${ }^{7}$

Therefore, to assess the welfare effect of the tariff, we simply have to assess the welfare effect of the wage subsidy $d t$ on low skill workers. It is useful to compare the wage subsidy with an income tax cut for the low skilled $d T_{1}=-l_{1} d t$. As we start from an optimal income tax, this income tax change has no first order effect on welfare. Let us show why the wage subsidy is superior to the income tax change and hence has a positive first order effect on welfare.

The wage subsidy has the same effect on both the utility of the unskilled and the same mechanical effect on tax revenue (ignoring behavioral responses) as the income tax change. Let us see why the wage subsidy does better on incentives than the income tax cut. Equation (1) shows that the high skilled person mimicking the low skilled does not benefit from the low skill wage subsidy because the high skill wage $w_{2}$ is not affected by the subsidy. Intuitively, the wage subsidy allows to target redistribution to the low skilled without affecting the incentives of the high skilled because when a high skilled reduces labor supply to imitate a low skilled person, he remains in the high skilled sector and thus does not benefit from the wage subsidy. On the other hand, equation (1) shows that the high skill mimicking the low skill benefits from the income tax cut $d T_{1}$. Therefore, a modification of the income tax in favor of the low skilled is going to affect labor supply of the high skilled as well because the tax schedule is common to both types. Therefore, it is clear that, for incentive reasons, the wage subsidy is preferable to the income tax cut. ${ }^{8}$

\subsection{The long-run or occupational choice model}

In the long-run model, individuals choose their occupation according to the relative rewards in each occupation. As it is plausible that the hours choice is of second order in the long run,

\footnotetext{
${ }^{7}$ In short, the government can replicate the commodity tax $d t$ on good 1 using a small income tax change $d T$ such that $d T_{i}=c_{1}^{i} d t$ where $c_{1}^{i}$ denotes consumption of good 1 by type $i$. Because of the separability assumption, the incentive compatibility constraint remains satisfied. As the income tax is optimal, this change (and hence the small commodity tax) has no first order effect on welfare.

${ }^{8}$ This can be shown formally using Lagrangian analysis. The first order effect on the Lagrangian of introducing a wage subsidy $d t$ is equal to the first order effect of introducing $d T_{1}=-l_{1} d t$ (which is zero at the optimum) plus an extra term $\lambda C^{\prime}\left(w_{1} l_{1} / w_{2}\right)>0(\lambda$ is the multiplier of the constraint (1)) showing that a wage subsidy is desirable.
} 
we assume labor supply is fixed (at unity) once a type of job is chosen. Therefore a given individual decides whether to work in an unskilled occupation or a skilled occupation depending on the after-tax incomes $w_{1}-T_{1}$ and $w_{2}-T_{2}$ in each occupation. Individuals differ in their tastes for work in each occupation. It may be easier for example for more educated people to handle a skilled occupation that for less educated people. We assume that the tastes for work are smoothly distributed across individuals and that the population is large enough so that the proportion of individuals who choose to work in a each occupation is a continuous function of after-tax incomes $w_{i}-T_{i} \cdot{ }^{9}$. We assume therefore that the total population is a continuum normalized to one and that the number of people in the low skilled job depends continuously on $w_{1}-T_{1}, w_{2}-T_{2}$, and the price level $q$. We denote by $f=f\left(w_{1}-T_{1}, w_{2}-T_{2}, q\right)$ the fraction of individuals who choose the low skilled occupation. Behavioral responses are built into the function $f\left(w_{1}-T_{1}, w_{2}-T_{2}, q\right)$. Presumably, $f$ is increasing in $w_{1}-T_{1}$ because if after-tax income in the low skilled occupation increases while prices and after-tax income in the high skilled occupation remain constant, low skilled occupations become more attractive and some high skilled workers may switch to low skilled occupations. Similarly, $f$ is presumably decreasing in $w_{2}-T_{2}$.

The government sets an income tax $\left(T_{1}, T_{2}\right)$ so as to maximize a weighted sum of utilities subject a budget constraint. We assume that the government also imposes a tariff $t$ on good 1 . Production of good 1 is equal to the number $f$ of workers in the low skilled occupation. Total consumption of good 1 is denoted as above by $C_{1}$ and thus net imports are equal to $C_{1}-f$. Thus, the budget constraint of the government is $f T_{1}+(1-f) T_{2}+t\left(C_{1}-f\right) \geq 0$. We assume that the government maximizes a social welfare function $W$ which is a weighted sum of individual utilities subject to the budget constraint.

As before, starting from a situation with no tariffs, we want to know whether imposing a tariff can improve welfare. As shown above, imposing a tariff $d t$ is equivalent to imposing a commodity tax $d t$ on good one and a wage subsidy $d t$ on low skilled jobs. As in the hours choice model, the small commodity tax has no first order effect on welfare because of separability between consumption and labor choices.

In the present model, workers base their decision on after-tax incomes $w_{i}-T_{i}$. Thus increasing

\footnotetext{
${ }^{9}$ This issue is treated rigorously in Section 3
} 
the pre-tax wage $w_{1}$ by $d t$ dollars is strictly equivalent to decreasing the income tax $T_{1}$ by $d t$ dollars from the workers' perspective. Obviously, the fiscal cost for the government of a wage subsidy $d t$ on low skilled workers is equal to a reduction $d T_{1}=-d t$ of the income tax on low skilled workers. Therefore, the wage subsidy $d t$ is exactly equivalent to a reduction in the income $\operatorname{tax} d T_{1}=-d t$. Consequently, the small tariff can be exactly replicated using the income tax instrument. As the income tax is optimal, a small change around the optimum cannot improve welfare. As a result, the small tariff $d t$ does not improve welfare either, implying that there should be no tariff at the optimum.

\subsection{Interpretation}

The desirability of tariffs hinges crucially on whether tariffs constitute a new tax instrument that cannot be replicated with the domestic income or commodity taxes. In the simple model we have considered, imposing a tariff on low skilled intensive goods amounts to imposing a wage subsidy to low skilled occupations which narrows the wage gap between the two types of jobs. In the short-run model, individuals are stuck in their low or high skill occupation and can only vary hours of work within their occupation. Therefore, a wage subsidy specific to the low skilled has no adverse effect on the incentives to work of the high skilled. In contrast, an income tax cut for the low incomes would make it more attractive for the high skilled to mimic the low skilled and take advantage of the tax cut. Therefore, in the short-run model, tariffs enhance the redistributive power of the government, and are therefore desirable. In the long run, however, reducing the gap between high and low wage earners with a low skilled wage subsidy will induce high skilled workers to move to less skilled occupations, and thus, the wage subsidy is directly equivalent to a reduction in the income tax burden of the low skilled. Therefore, tariffs or direct wage subsidies can be replicated by the income tax instrument and thus are useless instruments in a long-run context with optimal income taxation.

The short-run model predicts that a low skilled wage subsidy would have no effect on labor supply of the high skilled whereas the long-run model predicts that such a wage subsidy would have exactly the same effect as a cut in the income tax for low incomes. Therefore, in order to assess which of the two models is the closest to the real situation, the critical empirical question is whether a wage subsidy to the low skilled would indeed have a smaller effect on incentives 
of the high skilled than an equivalent cut in the income tax at the low end. Unfortunately, the empirical literature on the labor supply responses to taxation does not offer a direct answer to this question but some elements should be noted.

Labor supply studies find little cross-sectional relation between hours of work and the wage rate, suggesting that narrowly defined hours of work are not very sensitive to the wage rate (see the surveys by Pencavel (1986) and Blundell and MaCurdy (1999)). However, one should not interpret the Stiglitz (1982) model too narrowly. When the income tax increases, the high skilled might respond by reducing effort on the job producing a significant decrease in earnings but with little change in hours of work. It is important therefore to look at overall earnings and not only hours of work.

Studies focusing on overall income or earnings tend indeed to find larger elasticities than hours of work studies (see e.g., Feldstein (1995) for a seminal study of the response of taxable income to tax rates and Gruber and Saez (2000) for a recent survey of this literature). By itself, this piece of evidence is not conclusive for our problem because this type of response could be compatible both with the short-run model and the long-run model. It fits with the short-run model if, as mentioned just above, individuals vary their intensity of work on the job in response to taxation. It fits with the long-run model if individuals vary their labor supply in order to get into different occupations, either by getting promoted more quickly or more slowly within a firm, or by moving to other sectors. The empirical literature does not give much information on this issue.

Related to this point however, a strand of the labor supply literature focuses on the response along the extensive margin, namely dropping out or entering the labor force. This margin has been shown to be sensitive to the net-of-tax wage rate, especially for secondary earners (see e.g., Meyer and Rosenbaum (2001)). This suggests that the response along the occupation margin might be more important than the response along the intensity of work on the job, at least for low skilled workers.

Last, following the path-breaking modeling work of Becker (1964), there has been substantial effort devoted to the estimation of the response of education and human capital accumulation choices to the salaries and rewards in different occupations (see e.g., the survey of Freeman (1986)). The literature finds evidence of substantial elasticities of the supply of education 
with respect to salaries, suggesting that the long-run occupational choice responses are large. Therefore, it is reasonable to think that the response of education to changes in the degree of the progressivity of taxation is also significant and plausibly large. ${ }^{10}$ Consequently, ignoring this response completely as in the Stiglitz (1982) model is not realistic.

The remaining of the paper considers a generalization of the model of occupational choice developed in Section 2.2 and shows that, contrary to the hours choice model sketched in Section 2.1 , the important properties of optimal tax structures, namely production efficiency, the Taxformula result and the Atkinson-Stiglitz theorem remain true.

\section{A General Model of Occupational Choice}

In this section, we present a general model of occupational choice with many commodities and a general production function. The core of the argument is to note that this model is a generalized version of the economy analyzed by the seminal paper of Diamond and Mirrlees (1971). As a result, we will show that this occupational model inherits the key properties of the DiamondMirrlees model, namely production efficiency, the Tax Formula result, and that Atkinson-Stiglitz theorem also carries over to that model.

\subsection{The Model}

In the model, each individual chooses an occupation or job $i$ among a set of $I+1$ possible occupations $\{0,1, . ., I\}$. We assume that job 0 is non participation in the labor force. Once a job is chosen, hours of work are fixed at unity. In other words, the only margin of decision for individuals is the occupation margin and the hours of work margin is inelastic. As discussed in Section 2, this captures a long-run model of labor supply or skill acquisition decision and is a good representation of the real world if the long-run labor supply responses through educational and occupational choices dwarf the short-run labor supply responses through hours of work or intensity of work within a given occupation. The key assumption is that different jobs do not pay the same wage: $w_{i} \neq w_{j}$ for any $i \neq j$. This assumption is almost surely satisfied as

\footnotetext{
${ }^{10}$ Unfortunately, there appears to be no convincing study of the direct effect of income taxation of the supply of education and occupations.
} 
we posited a finite number of occupations. Thus, without loss of generality, we assume that $w_{0}=0<w_{1}<. .<w_{I}$. The government sets taxes as a function of income $T_{i}=T\left(w_{i}\right)$. I denote by $m_{i}=w_{i}-T_{i}$ after-tax income in job $i$. Because wages are different in each occupation, imposing the income tax amounts to imposing differentiated tax rates on the supply of each occupation. I come back in detail to this important point at the end of the Section.

As in the Diamond and Mirrlees (1971) model, in addition to these $I$ labor inputs to production, we assume that there are $K$ consumption goods. We denote by $c$ the vector on consumption for a given individual and by $\bar{p}$ and $\bar{q}$ the before and after-tax prices of consumption goods. As in Diamond and Mirrlees (1971), there is a general production function defining the production possibility set linking the $K$ consumption goods and the $I$ labor inputs. As is standard, I assume that the production function has constant returns to scale or that the government can fully tax pure profits.

We assume that there is continuum of individuals of measure one, and that each individual is indexed by $n$ belonging to a general index set $\mathcal{N}$ possibly multi-dimensional. Individual $n$ maximizes a utility function $u^{n}(c, i)$ which depends on the vector of consumption goods $c$ and on the job $i$ chosen subject to the budget constraint $\bar{q} \cdot c \leq m_{i}$. The individual characteristic $n$ embodies both tastes for work and skills. For example, a hard working or skilled individual will find it easier to choose a more demanding or highly skilled occupation.

In order to see the link between the present model and the standard Diamond-Mirrlees economy, it is useful to treat symmetrically the consumption decision and the job choice. Therefore, I denote by $m=\left(m_{0}, m_{1}, . ., m_{I}\right)$ the vector of after-tax incomes, and by $p=(\bar{p}, w)$ and $q=(\bar{q}, m)$ the before and after-tax price vector of goods and wages, and by $\pi=(t,-T)=q-p$ the vector of tax rates. I denote by $c^{n}$ the individual consumption choice vector. Similarly, the job choice $i$ of individual $n$ can be denoted as $d^{n}=-(0, . ., 0,1,0, . ., 0)$ where $d^{n}$ is a vector of size $I+1$ and the unique 1 in vector $d^{n}$ is the $(i+1)$-th element. Therefore, I can summarize total demand of individual $n$ by the $K+I+1$ vector $x^{n}=\left(c^{n}, d^{n}\right)$. Individual $n$ picks $x^{n}$ so as to maximize $u\left(x^{n}\right)$ subject to $q \cdot x^{n} \leq 0$. Let us denote by $x^{n}(q)$ the individual (net) demand vector, and by $V^{n}(q)$ the indirect utility function arising from this maximization program. Put in that form, this model looks identical to a Diamond-Mirrlees economy. The unique and key difference is that the job choice $d^{n}$ belongs to a discrete set (as we assume that individuals cannot choose a 
convex combination of occupations). As a result, the individual demand $x^{n}(q)$ is discontinuous at points $q$ where the individual is indifferent between two occupations. ${ }^{11}$ However, as we will see, this discontinuity at the individual level is going to be smoothed out at the aggregate level under some simple conditions.

Total aggregate demand is denoted by $X(q)$ and is defined as

$$
X(q)=\int_{\mathcal{N}} x^{n}(q) d \nu(n)
$$

where $\nu(n)$ denotes the distribution of individuals over $\mathcal{N}$. We denote by $C(q)$ the vector of aggregate demand for consumption goods and $f_{i}(q)$ the fraction of individuals who choose occupation $i$ when facing prices $q$. It is important to note that the behavioral responses to income taxation are fully embodied in the aggregate supply functions $f_{i}(q)$. For example, when $m_{i}$ declines, individuals may move out of occupation $i$ producing a decrease in $f_{i}$ and corresponding increase in the supply of other close occupations. By definition, $X(q)=\left(C(q),-f_{0}(q), . .,-f_{I}(q)\right)$. The government sets taxes $\pi$ so as to maximize a weighted sum of individual utilities. The social welfare function is defined as

$$
V(q)=\int_{\mathcal{N}} \mu(n) V^{n}(q) d \nu(n)
$$

where $\mu(n)$ is a measure of non-negative weights. Exactly as in Diamond and Mirrlees (1971), the government maximizes the social welfare function $V(q)$ subject to a budget constraint and a production constraint. The budget constraint states that total tax collected $\pi \cdot X(q)$ must be larger that some exogenous amount $E$. The production constraint states that aggregate demand $X(q)$ must be technically feasible. Diamond and Mirrlees (1971) show that it is mathematically equivalent to assume that the government has full control of the production decision. Therefore, the two constraints can be collapsed into a single constraint $X(q) \in G$ where $G$ is the production set. The production set $G$ embodies both the revenue requirement $E$ and the technological feasibility constraint.

\footnotetext{
${ }^{11}$ Note that the indirect utility $V^{n}(q)$ is continuous as soon as we assume that $u^{n}($.$) is continuous.$
} 


\subsection{Properties of the Occupational Model}

\section{- Production Efficiency}

Diamond and Mirrlees (1971) show that, when aggregate demand $X(q)$ and the indirect social welfare function $V(q)$ are continuous in $q$ (THEOREM 4, p.23), at the optimum $q^{*}$, aggregate demand $X\left(q^{*}\right)$ is on the frontier of the set $G$. This is the Production efficiency theorem. In the Diamond-Mirrlees economy, continuity follows directly from convexity of preferences. In the occupational model of the present paper, continuity of aggregate demand is obtained by assuming that the number of individual is large and preferences regularly distributed. More precisely

Assumption 1 For each individual n, preferences are strictly convex and regular enough so that individual the demand function $x^{n}(q)$ is regular at any point $q$ where individual $n$ is not indifferent between two or more job choices.

For any $q>>0$, the set $A_{q}$ of individuals $n$ who are indifferent between two or more job choices is of measure zero.

By regular, we mean continuous and differentiable. As discussed above, individual demand is obviously discontinuous at price levels $q$ where the individual switches between occupations (and hence is indifferent between two or more occupations). The first part of assumption 1 simply states that, outside these singular points, demand functions are well behaved and regular. The second part of assumption 1 states that these singular points are smoothly distributed across individuals precisely so that there are no jumps in the aggregate.

Lemma 1 Under Assumption 1, aggregate demand $X(q)$ and indirect social welfare $V(q)$ are regular in $q$.

The technical proof is presented in appendix. Using Lemma 1 and the same proof as in Diamond and Mirrlees (1971), we obtain immediately

Proposition 1 Under Assumption 1, at the optimum, there should be production efficiency in the occupational choice model. 


\section{- Tax-Formula and Optimal Income Taxation}

From the maximization program described above, $\max V(q)$ subject to $X(q) \in G$, Diamond and Mirrlees (1971) derive first order conditions which take the following simple form,

$$
\frac{\partial V}{\partial q_{k}}=\lambda \sum_{j} p_{j} \frac{\partial X_{j}}{\partial q_{k}},
$$

where $\lambda$ is a positive multiplier and $X_{j}$ is aggregate demand of good (or factor) $j$. The important property embodied in equation (5) and that I called the Tax-Formula result in the introduction section is that the first order condition (5) does not depend explicitly upon the degree of substitution between factors in the production function. Put differently, in the derivation of equation (5), one can assume that producer prices $p_{j}$ are constant. Of course, in any practical application with endogenous prices, the prices $p_{j}$ at the optimum depend indirectly on the demand for goods and factors and thus on the vector of taxes $\pi$. However, the Tax-Formula result simplifies considerably the theoretical analysis of equation (5).

In the present occupational model, the tax formula result is going to be valid as soon as the functions $V(q)$ and $X(q)$ are differentiable in $q$. Therefore

Proposition 2 Under Assumption 1, at the optimum, the tax formula (5) applies in the occupational choice model.

The Tax-Formula result of Proposition 2 is important for optimal income taxation. The occupational model with one consumption good and multiple job choices can be seen as a model of optimal non-linear taxation. The government chooses tax rates on each occupation to maximize welfare taking into account the potentially adverse effect of taxation on incentives to work. This model was first developed by Piketty (1997) in the case of three occupations and a Rawlsian welfare criterion and extended by Saez (2000a) to any number of occupations and any social welfare function to study the problem of optimal transfers to low incomes.

The literature on non-linear income taxation that grew out of the original contribution of Mirrlees (1971) has considered models where there is perfect substitution of labor inputs in the production function and where the space choice for individual earnings is an interval instead of a discrete set. Piketty (1997) and Saez (2000a) have shown that the discrete model leads to 
formulas of the same form as in the standard continuum case. Therefore, nothing fundamental is changed by assuming a discrete set of earnings outcomes. In that context, the Tax Formula shows immediately that, even if we relax the assumption that labor inputs are perfect substitutes, the same optimal tax formulas apply. This shows that optimal income tax formulas and results remain valid when the perfect substitution assumption is dropped in the context of the long-run occupational choice model where the income tax amounts to imposing differentiated tax rate on each occupation.

It is important to understand that this is not contradictory with Stiglitz (1982) who shows that relaxing the perfect substitution assumption alters optimal income tax formulas. Stiglitz (1982) result is obtained in a model where individuals are either skilled or unskilled and vary their labor supply within occupations. As a result and as explained above, the non-linear income tax is not equivalent to differentiated tax rates on labor inputs, and thus the Tax-Formula result breaks down. The Mirrlees (1971) continuous model can be interpreted as an hours of work model where skills are fixed ${ }^{12}$ in which case optimal tax formulas are not robust to relaxing the assumption of perfect substitution. But the Mirrlees (1971) model can also be interpreted as an occupation choice model where individuals choose their occupation among a continuum. In that case, the non-linear income tax is directly equivalent to differentiated tax rates on each occupation and thus the standard optimal tax formulas are still valid in the case of imperfect substitution. ${ }^{13}$

\section{- Complementary Commodity Taxation}

Atkinson and Stiglitz (1976) showed in the context of the Mirrlees (1971) model of income taxation with many consumption goods that in the presence of an optimal non-linear income tax, commodity taxation is useless when utility is weakly separable between leisure and consumption goods. Atkinson and Stiglitz proved their result in a fixed price model (i.e. with

\footnotetext{
${ }^{12}$ That was the interpretation given originally in Mirrlees (1971)

${ }^{13}$ As there is a continuum of choices in the Mirrlees (1971) model, one would have to extend the DiamondMirrlees model to the case with a continuum of factors. We conjecture that it is possible to do so rigorously and describe regularity conditions that would make Propositions 1 and 2 true in that context. However, as the mathematical degree of complication would be far greater, we think that the finite case provides an approximation good enough and thus do not pursue the continuum case any further.
} 
perfect substitution of labor types in the production function). As shown by Naito (1999), the Aktinson-Stiglitz theorem breaks down with imperfect substitution in the context of the hours choice model. However, we are going to show that the theorem is robust in the occupational choice model.

More precisely, the weak separability assumption takes the following form. Individual $n$ has a utility function of the form $U^{n}(v(c), i)$ where $i=0, . ., I$ is the occupation choice, and $v(c)$ is the sub-utility of consumption goods. ${ }^{14}$ We can easily prove the following proposition,

Proposition 3 In the occupation choice model, the Atkinson-Stiglitz Theorem remains valid with imperfect substitution in labor types. Namely, weak separability implies that there no need to tax commodities at the optimum.

Proof: The proof goes in two steps. First, we need to show that, assuming fixed prices, the Atkinson-Stiglitz theorem goes through in the discrete model we are considering. The easiest way to see this is to use the proof method developed by Christiansen (1984).

Weak separability implies that the consumption choice vector can be written as $c(\bar{q}, m)$ where $\bar{q}$ is the vector price of goods and $m$ is disposable income (equal to $m_{i}=w_{i}-T_{i}$ in occupation $i)$. Let us denote by $V(\bar{q}, m)=\max _{c} v(c)$ s.t. $\bar{q} c \leq m$. Individual $n$ then chooses $i$ to maximize semi-indirect utility function $U^{n}\left(V\left(\bar{q}, m_{i}\right), i\right)$.

Starting from no commodity taxation and optimal income taxation, let us consider a small increase $d t_{1}$ in (say) $t_{1}$. The proof consists in showing that the effects on tax revenue and welfare of this change can be reproduced by a small income tax change such that $d T_{i}=c_{1}\left(\bar{q}, m_{i}\right) d t_{1}$ for each $i=0, . ., I$. The proof is sketched in appendix. As the income tax is optimal, the income tax change, and hence the commodity tax change $d t_{1}$ do not improve welfare, implying that no commodity taxation is optimal.

Second, if we now assume that prices are variables, using Proposition 2, we can apply the Tax-Formula result stating that the first order conditions for optimality with variable prices take the same form as when prices are fixed. From step one, optimal tax formulas imply that commodity tax rates are zero in the fixed price model, therefore, commodity tax rates are also zero with variable prices. Q.E.D.

\footnotetext{
${ }^{14}$ As discussed in Saez (2000b), the fact that the function $v($.$) is common to all individuals is often overlooked$ but is as important as the weak separability assumption to obtain the Atkinson-Stiglitz result.
} 


\section{- Caveat}

As discussed in the beginning of this section, the key assumption needed to obtain Propositions 1,2 , and 3 is that each income level corresponds to a unique occupation. This assumption is innocuous in the case of a discrete number of jobs. However, in the real world situation, there is a very large number of sectors and occupations, and individuals earning the same income can end up being in very different occupations. In that case, a general income tax cannot replicate any pattern of specific taxes for each occupation type and the formal results of Propositions 1 , 2 , and 3 break down.

However, it is important to note that this lack of robustness is very different from the one described in Stiglitz (1982) and Naito (1999). Indeed, the results of Stiglitz (1982) and Naito (1999) are important, not only because they show that the normal theory is not robust, but also and mostly because they give a clear sense of how policy should be tilted relative to the normal theory. Namely, the analysis of Naito (1999), as discussed in Section 2.1, provided an unambiguous justification for providing wage subsidies for industries employing low skilled workers or imposing tariffs on low skilled intensive goods.

In the occupational model, the income tax cannot discriminate between occupations generating the same earnings. Therefore, in that case, occupation specific subsidies constitute a policy instrument more powerful than the income tax. However, in contrast to Naito (1999) situation, it is not clear whether these subsidies should be tilted toward low earnings occupations rather than higher earnings ones. Therefore, introducing this additional layer of complication does not provide any clear-cut policy recommendation as to what type of goods and industries should be subsidized. As a result, this complication introduces a second order deviation from the set-up we considered and the Propositions obtained in this paper are likely to be still an accurate approximation to the optimal policy.

\section{Conclusion}

This paper has shown that, in a long-run context where individuals respond to tax incentives through the occupation margin, the key results of optimal tax theory, namely production efficiency, the irrelevance of substitution in production for optimal tax formulas, and the Atkinson- 
Stiglitz theorem on commodity taxation, are robust to the relaxation of the assumption of fixed priced and perfect observability of labor types. This stands in contrast to a short-run situation where individuals are stuck into their occupations and can only adjust labor supply on the job. Stiglitz (1982) and Naito (1999) showed that, in that context, the results of optimal taxation are not robust. The reason for the difference is that, in the long-run, individuals move from occupation to occupation depending on the after-tax rewards in each occupation, and therefore, the (non-linear) income tax has the same effects as differentiated tax rates on labor types.

These results have important tax policy implications: In a short-run perspective, indirect tax instruments such as production subsidies on low skilled labor intensive sectors, tariffs or commodity taxes on high skilled labor intensive goods, are desirable to complement the redistribution achieved by progressive income taxation. However, In a long-run perspective, these indirect tax instruments are sub-optimal and redistribution should be achieved solely with the direct progressive income tax.

This set of prescriptions fits well with the real world economy. Unions support tariffs or production subsidies because union members are stuck to occupations. Using redistributing tools which lead to production inefficiencies might then be a helpful way to manipulate wage rates and improve redistribution. The short-run might indeed be one or two decades long which is very long given the time horizon of finitely lived workers. As tariffs or production subsidies can serve the general interest in the short-run (as opposed to mere particular interests), it is rational that some political parties support these policies. ${ }^{15}$

On the other hand, in a long-run perspective, it would be unwise for the government to try to save using large subsidies or tariffs production sectors that can no longer compete with newer technologies or foreign production. Therefore, in the long run context, it makes sense for the government to keep production efficient and let supply adjust to the new economic situation. In other words, it cannot be optimal for a government to go against efficient technological advances in the long-run. In this context, redistribution should take place, through a general income tax and consumption taxes that do not lead to production inefficiencies.

\footnotetext{
${ }^{15}$ Diamond (1982) develops a simple model where industries decline and workers face moving costs of switching to another industry. In that situation, it might be optimal for the government to provide subsidies to moving costs or to declining industries. The present analysis focuses on the long-run and thus ignores the moving cost issue.
} 
The corporate income tax in the US provides a good example of this short-run versus longrun contradiction. The corporate income tax leads to production inefficiencies because different sectors are treated differently. It is believed that the corporate income tax treats differently sectors because some sectors successfully lobby to obtain tax preferences. ${ }^{16}$ In the short-run, a government might find it socially beneficial to provide tax breaks in some sectors in order to affect wages and enhance redistribution in a way the income tax cannot. However, in the long-run, these inefficiencies cannot be optimal and tax preferences are cleared from time to time through a general corporate income tax reform (as happened for example in the U.S. with the Tax Reform Act of 1986).

It is therefore important to assess which of the two models (short-run versus long-run) fits the best with the real situation. As we discussed, these two models could be distinguished by the empirical analysis of labor supply responses. This literature gives clear evidence that the occupation choice margin is sensitive in the long-run to rewards, while the evidence on responses to incentives within occupations appears to be weaker. A sharper test would be to test directly whether a low wage subsidy has negative incentive effects for (slightly) higher wage earners. The short-run model predicts it should not while the long run model predicts it should have exactly the same effects as a corresponding cut in the income tax for low wage earners. This important empirical question is left for future research.

\footnotetext{
${ }^{16}$ See for example Boskin (1996) for an exposition of this view.
} 


\section{Appendix}

\section{- Proof of Lemma 1}

The regularity of $X(q)$ follows from Lebesgue's Dominated Convergence Theorem. Let $q>>$ 0 and $q^{j}$ be a sequence converging to $q$. By the regularity assumption on utility functions, $x^{n}($. is continuous at $q$ when the individual $n$ is not indifferent between two or more job choices when facing price $q$. By assumption, this is true except for a set of measure zero. Therefore, $x^{n}\left(q^{j}\right) \rightarrow x^{n}(q)$ when $j \rightarrow \infty$ almost surely. For $q>>0$, it is clear that the demand functions $x^{n}(q)$ are bounded. Thus, by the theorem of dominated convergence, $X\left(q^{j}\right) \rightarrow X(q)$, implying that $X(q)$ is continuous. The proof of the continuity of $V(q)$ is even simpler because the individual $V^{n}(q)$ functions are continuous.

The proof of the differentiability of $X(q)$ (and $V(q)$ ) proceeds in the same way. Q.E.D.

\section{- Proof of the Atkinson-Stiglitz result in the discrete model}

As mentioned in the text, we have to show that the income tax change such that $d T_{i}=$ $c_{1}\left(\bar{q}, m_{i}\right) d t_{1}$ for each $i=0, . ., I$ has the same effect on tax revenue and welfare as the commodity tax change $d t_{1}$. Note that the change $d T_{i}$ is well defined because the function $c_{1}\left(\bar{q}, m_{i}\right)$ is the same for all individuals. That is why the weak separability (and uniform sub-utility $v(c)$ ) assumption is key to the result.

First, from Roy's identity, we have $V_{t_{1}}=-V_{m} c_{1}$, thus both changes have the same effect on individual utility and hence on welfare. Second, because both changes have the same effect on the sub-utility $V(\bar{q}, m)$, any individual who switches occupations because of one the tax change also switches occupations because of the other one (and vice-versa). Therefore, the behavioral responses to the two tax changes are identical. Thus the effect on tax revenue due to behavioral responses is the same in both cases. Last, the mechanical change in tax revenue is the same in both cases and equal to $d t_{1} \sum_{i} f_{i} c_{1}\left(\bar{q}, m_{i}\right)$. Therefore, the small commodity tax is fully equivalent to the small income tax change. 


\section{References}

[1] Atkinson Anthony B. and Joseph E. Stiglitz. (1976), "The Design of Tax Structure: Direct versus Indirect Taxation." Journal of Public Economics, 6, 55-75.

[2] Becker, Gary S. (1964) Human Capital. New-York: National Bureau of Economic Research.

[3] Blundell, Richard and Thomas MaCurdy, "Labor Supply: A Review of Alternative Approaches", in O. Ashenfelter and D. Card, eds., Handbook of Labor Economics, Volume 3A, 1999.

[4] Boskin, Michael. (1996), Frontiers of Tax Reform, Stanford: Hoover Institution Press.

[5] Christiansen, Vidar A., (1984). "Which commodity taxes should supplement the income tax?", Journal of Public Economics, 24, 195-220.

[6] Diamond, Peter (1982), "Protection, Trade Adjustment Assistance, and Income Distribution." in Jagdish N. Bhagwati, ed., Import Competition and Response, Chicago: The University of Chicago Press.

[7] Diamond, Peter and James Mirrlees (1971), "Optimal Taxation and Public Production." American Economic Review, 61, 8-27 and 261-278.

[8] Dixit, Avinash and Victor Norman (1980), Theory of International Trade, Cambridge: Cambridge University Press.

[9] Dixit, Avinash and Victor Norman (1986), "Gains from Trade without Lump-Sum Compensation." Journal of International Economics, 21, 111-122.

[10] Feldstein, Martin (1995), "The Effect of Marginal Tax Rates on Taxable Income: A Panel Study of the 1986 Tax Reform Act." Journal of Political Economy, 103(3), 551-572.

[11] Freeman, Richard. (1986), "Demand for Education" in O. Ashenfelter and R. Layard (eds.), Handbook of Labor Economics, Amsterdam: North-Holland, 357-386.

[12] Gruber, Jonathan and Emmanuel Saez, (2000) "The Elasticity of Taxable Income: Evidence and Implications.", NBER Working Paper No. 7512, forthcoming Journal of Public Economics. 
[13] Guesnerie, Roger (1998), "Peut-on Toujours Redistribuer les Gains à la Spécialisation et à l'Echange? Un Retour en Pointillé sur Ricardo et Heckscher-Ohlin.", Revue Economique, $49,555-79$.

[14] Meyer, Bruce and Daniel Rosenbaum (2001), "Welfare, the Earned Income Tax Credit, and the Labor Supply of Single Mothers," Quarterly Journal of Economics, 106, 1063-1114.

[15] Mirrlees, James A. (1971), "An Exploration in the Theory of Optimal Income Taxation." Review of Economic studies, 38, 175-208.

[16] Naito, Hisahiro. (1996), "Tariffs and Production Subsidies as Devices to Relax the Incentive Problem of a Progressive Income Tax System.", Research Seminar in International Economics Discussion Paper No. 391, University of Michigan.

[17] Naito, Hisahiro. (1999), "Re-Examination of Uniform Commodity Taxes under a NonLinear Income Tax System and its Implication for Production Efficiency." Journal of Public Economics, 71, 165-188.

[18] Pencavel, John. (1986), "Labor Supply of Men." in O. Ashenfelter and R. Layard (eds.), Handbook of Labor Economics, Amsterdam: North-Holland, 3-102.

[19] Piketty, Thomas. (1997), "La Redistribution Fiscale face au Chômage." Revue Française d'Economie, 12(1), 157-201.

[20] Sadka, Efraim (1976), "On Income Distribution, Incentive Effects and Optimal Income Taxation." Review of Economic Studies, 43(2), 261-8.

[21] Saez, Emmanuel. (2000a), "Optimal Income Transfer Programs: Intensive Versus Extensive Labor Supply Responses.” NBER Working Paper No. 7708, forthcoming Quarterly Journal of Economics.

[22] Saez, Emmanuel. (2000b), "The Desirability of Commodity Taxation under Non-Linear Income Taxation and Heterogeneous Tastes.” NBER Working Paper No. 8029, forthcoming Journal of Public Economics. 
[23] Saez, Emmanuel. (2001), "Using Elasticities to Derive Optimal Income Tax Rates.", Review of Economic Studies, 68, 205-229.

[24] Seade, Jesus K. (1977), "On the Shape of Optimal Tax Schedules." Journal of Public Economics, 7(2), 203-236.

[25] Spector, David. (1999), "Is it Possible to Redistribute the Gains from Trade Using Income Taxation?", MIT mimeograph.

[26] Stiglitz, Joseph E. (1982), "Self-Selection and Pareto Efficient Taxation." Journal of Public Economics, 17, 213-240. 